\title{
PENGENDALIAN KESTABILAN TERBANG ROBOT PENJELAJAH UDARA DENGAN METODE HYBRID PID-FUZZY
}

\author{
Nur Yanti ${ }^{1}$, Fathur Zaini Rachman ${ }^{2}$, Suhaedi $^{3}$ \\ 1,2,3Politeknik Negeri Balikpapan \\ Email: ${ }^{1}$ nur.yanti@poltekba.ac.id, ${ }^{2}$ fozer85@gmail.com, ${ }^{3}$ suhaedi@ @oltekba.ac.id
}

(Naskah masuk:15 Oktober 2018, diterima untuk diterbitkan:29 Oktober 2018)

\begin{abstract}
Abstrak
Pengembangan robot dengan sistem kecerdasan buatan memiliki keunggulan, seperti pada robot penjelajah udara dimana pemanfaatannya dapat digunakan sebagai robot pemadam api pada kebakaran hutan, pengambilan gambar. Robot penjelajah udara beroperasi menggunakan empat rotor dan empat buah baling-baling. Karena kombinasi inilah sistem mampu mengendalikan gaya angkat pesawat, melalui kondisi torsi yang seimbang. Robot mampu melakukan pitch, yaw, dan roll menggunakan kendali empat rotor. Ketika robot penjelajah udara melakukan gerakan manuver, gerakan melayang (hovering) memerlukan kestabilan terbang, sehingga robot penjelajah udara ini dirancang dengan menggunakan sistem kendali hibrid PID-Fuzzy agar dihasilkan kestabilan terbang sesuai posisi ketinggian tertentu dan proses pendaratan. Metode penelitian meliputi perancangan rangkaian dan alat, pembuatan program untuk remote dan motor brushless, implementasi program pada kontroler, serta pengujian alat. Dengan kendali hibrid PID-Fuzzy diharapkan mengatasi berbagai masalah kendali saat terbang dengan mengubah nilai gain $K p, K i$, dan $K d$ dan mampu mengatasi sistem kendali robot yang nonlinier, sehingga dihasilkan kestabilan terbang robot yang baik sesuai tingkat ketinggian terbang dan saat pendaratan.
\end{abstract}

Kata kunci: kendali, kestabilan, PID-Fuzzy, robot

\section{STABILITY CONTROL FLYING THE AIR CONDITIONING ROBOT WITH HYBRID PID-FUZZY METHOD}

\begin{abstract}
The development of robots with artificial intelligence systems has advantages, such as in air explorers robots where their utilization can be used as fire fighting robots in forest fires, shooting. The air explorer robot operates using four rotor and four propellers. Because of this combination the system is able to control the lifting force of the aircraft, through a balanced torque conditions. The robot is able to pitch, yaw, and roll using the four rotor controls. When the air-cruise robot performs a maneuvering motion, hovering requires flying stability, so the air explorer robot is designed using a PID-Fuzzy hybrid control system to generate flying stability in a certain altitude position and landing process. Research methods include circuit design and tools, programming for remote and brushless motors, program implementation on controllers, and tool testing. With PID-Fuzzy hybrid control is expected to overcome the problems of control when flying by changing the gain value $\mathrm{Kp}, \mathrm{Ki}$, and $\mathrm{Kd}$ and able to overcome the nonlinear robot control system, resulting in good robot flying stability according to the level of flying altitude and when landing.
\end{abstract}

Keywords: control, stability, PID-Fuzzy, robot

\section{PENDAHULUAN}

Dunia robotika saat ini semakin berkembang seiring dengan semakin berkembangnya ilmu pengetahuan dan kebutuhan manusia akan suatu sistem yang dapat membantu memudahkan berbagai pekerjaan. Pengembangan keilmuan dibidang rekayasa dan non-rekayasa telah mengarah pada smart system (sistem cerdas). Sistem cerdas bertujuan membangun sistem digitalisasi melalui otomatisasi atau optimalisasi dari perangkat baik perangkat keras maupun perangkat lunak. Saat ini penanaman sistem cerdas pada robot menjadi trend issue, yang dapat menggantikan pekerjaan manusia atau pekerjaan yang tidak mampu dilakukan oleh manusia. Seperti halnya pada robot penjelajah udara (quadcopter) ini, sistem cerdas dibangun dengan tujuan untuk menjaga keseimbangan saat terbang, 
sehingga tercapai kesetabilan terbang. Robot penjelajah udara (quadcopter) adalah robot Unmanned Aerial Vehicle (UAV) yang termasuk kategori UAV micro dan banyak digunakan oleh beberapa lembaga atau instansi. Robot penjelajah udara memiliki beberapa kelebihan yang menjadikannya cocok untuk melakukan pekerjaan tertentu. Bentuknya yang kecil membuat robot penjelajah udara leluasa untuk bergerak di tempattempat yang sulit. Robot penjelajah udara juga dapat terbang secara vertikal, yang berarti ia tidak memerlukan landasan pacu untuk dapat terbang. Selain itu robot juga dapat bergerak ke delapan arah mata angin tanpa perlu memutar badannya terlebih dahulu. Jika dibandingkan dengan kendaraan udara bersayap. Robot penjelajah udara (quadcopter) merupakan UAV yang memiliki ciri khusus dan mudah dikenali yaitu ketika beroperasi menggunakan empat rotor dan empat buah balingbaling. Dua rotor berputar melawan arah jarum jam dan dua lainnya searah jarum jam. Karena kombinasi ini lah sistem mampu mengendalikan gaya angkat pesawat, melalui kondisi torsi yang seimbang. Sedangkan ketika dilihat dari segi vertical take off and landing aircraft (VTOL) robot penjelajah udara mampu melakukan pitch, yaw, dan roll menggunakan kontrol kendali empat rotor. Gerakan pitch atau gerakan menggangguk ke depan akan dilakukan dengan cara mengubah kecepatan pada pasangan baling-baling depan dan belakang. Sedangkan untuk melakukan gerakan roll atau gerakan menoleh ke kanan dan kekiri, robot akan melakukan perubahan kecepatan pada pasangan baling-baling kiri dan kanan. Serta gerakan sumbu vertical (yaw) dengan menurunkan kecepatan salah satu pasang baling-baling dan menaikan kecepatan pasangan lainnya. (Haryanto dkk, 2014). Pembuatan robot mengalami banyak permasalahan mulai dari keempat rotor yang tidak bisa menghasilkan gaya angkat, karena saat itu keempat rotor masih dirancang untuk berputar searah. Namun masalah ini dapat diatasi dengan cara mengubah arah putar secara berlawanan. Meski menghasilkan gaya angkat, tapi kinerja tidak bisa sempurna, karena untuk mengatur naik-turun dan maju-mundur belum bisa dilakukan. (Kumar dkk, 2014). Quadcopter dirancang dengan mempertimbangkan ketinggian terbang, sehingga dirancang sistem kendali ketinggian quadcoptermenggunakan PID (Gembong dkk, 2015).

Ketika robot penjelajah udara melakukan gerakan manuver, gerakan melayang (hovering) memerlukan kestabilan terbang, sehingga robot penjelajah udara ini dirancang dengan menggunakan sistem kendali hibrid PID-Fuzzy agar dihasilkan kestabilan terbang sesuai posisi ketinggian tertentu dan proses pendaratan. Pengendali PID terdiri dari tiga komponen yaitu proportional, integral , dan derivative yang dapat dipakai secara bersamaan maupun sendiri - sendiri tergantung dari respon yang diinginkan pada suatu sistem/ plant. (menggunakan Yusivar \& Jepry, 2010). Robot penjelajah empat rotor, dengan arah putaran dua rotor searah jarum jam $(\mathrm{CW})$ dan dua rotor berlawanan arah jarum jam (CCW). Dan hal ini digunakan sebagai dasar sistem untuk mengendalikan gerakan pesawat (Ricardo dkk, 2014).

\section{METODE PENELITIAN}

Metode penelitian meliputi perancangan rangkaian dan alat, pembuatan program untuk remote dan motor brushless, pembuatan alat, implementasi program pada kontroler, serta pengujian alat. Adapun metode yang digunakan ditunjukkan pada gambar 1 .

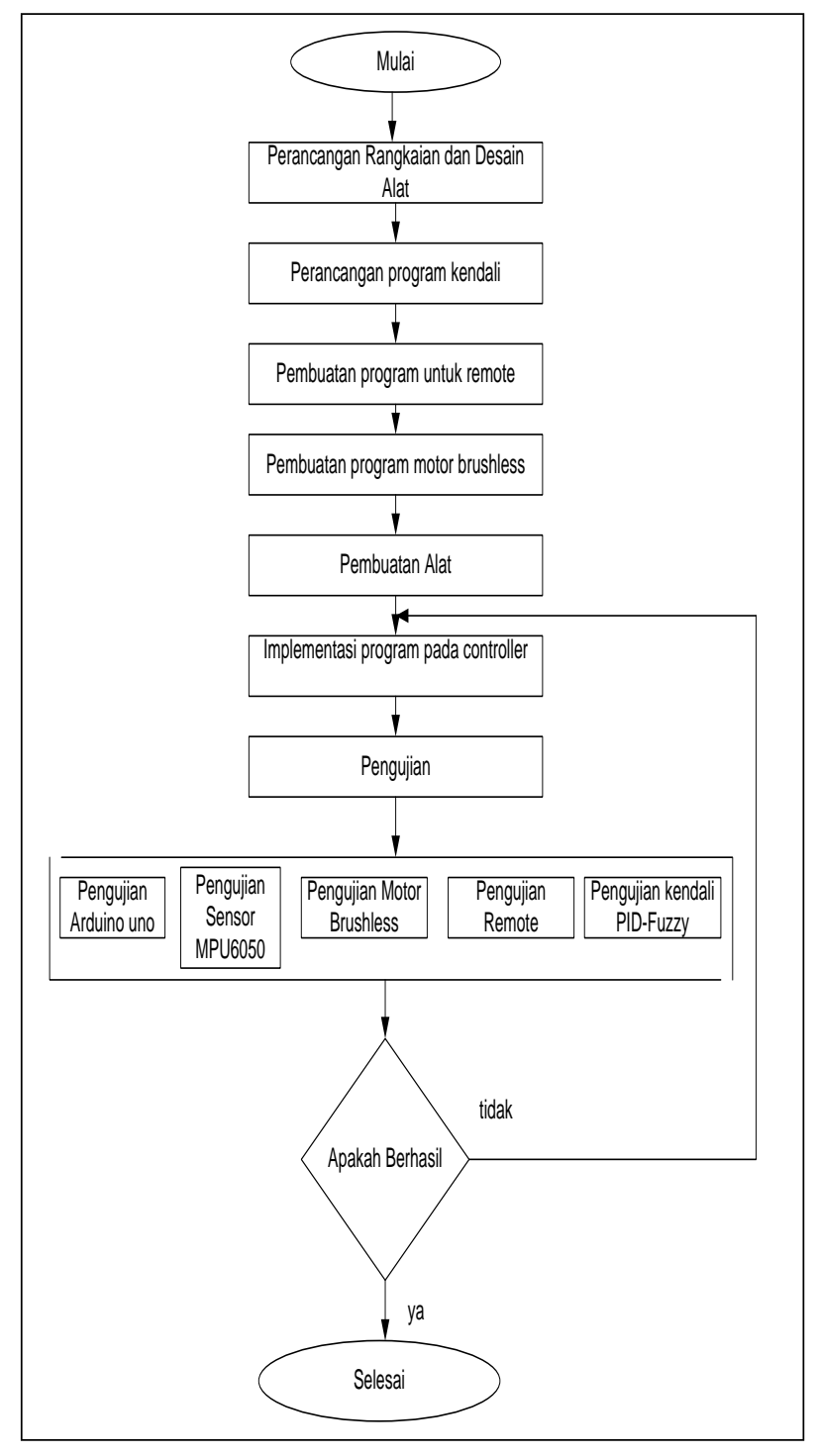

Gambar 1. Diagram alir metode penelitian.

Uraian dari metode penelitian yang dilakukan sebagai berikut :

Perancangan rangkaian dan alat. 
Langkah pertama dalam rancang bangun robot penjelajah udara (quadcopter) adalah membuat rancangan rangkaian dan alat berupa gambar rangkaian, desain layout, rancangan hardware serta komponen-komponen yang diperlukan untuk membangun robot.

Pembuatan program untuk remote dan motor brushless

Langkah berikutnya adalah pembuatan program untuk remote dan motor brusshless yaitu dengan membangun struktur pemrograman di mikrokontroller arduino uno. Selain pemprograman di arduino, juga menggunakan perangkat lunak MATLAB sebagai program simulink untuk PID dan fuzzy.

\section{Pembuatan alat.}

Tahap ini adalah pembuatan hardware dari robot penjelajah udara, terdiri dari rancang bangun rotor, motor brushlees, remote serta $\mathrm{I} / \mathrm{O}$ pada mikrokontroller arduino uno.

Implementasi program pada kontroler.

Rancangan program untuk remote, motor brushlees, serta program simulink MATLAB yang telah dibuat, diimplementasikan atau didownload ke kontroler untuk penggabungan seluruh perangkat lunak yang digunakan pada perancangan alat.

\section{Pengujian alat.}

Pengujian alat dilakukan pada masing-masing komponen utama dari robot penjelajah udara yaitu pengujian arduino uno, motor brushlees, sensor MPU6050, remote dan pengendali PID-Fuzzy. Setelah itu dilakukan penggabungan seluruh program pada mikrokontroler arduino uno, dilakukan pemasangan semua komponen hardware robot yang terdiri dari rotor, motor brushlees dan remote yang telah dibuat, dihubungkan ke mikrokontroler sebagai pengendali dari sistem secara keseluruhan. Kemudian dilakukan pengujian sistem secara keseluruhan untuk mengevaluasi error atau kendala yang masih terdapat pada robot penjelajah udara.

\section{PERANCANGAN}

Dari perancangan pengendalian kestabilan terbang pada robot penjelajah udara di dapatkan hasil sebagai berikut :

\section{Kontroler Arduino Uno}

Pada pembuatan robot ini digunakan arduino uno sebagai pengendali mikro atau mikrokontroler. Pada arduino uno dikoneksikan beberapa device yaitu sensor MPU6050, receiver dari Remote Control Fly Sky i6, serta 4 buah motor yang disambungkan dengan Electronic Speed Controller (ESC).

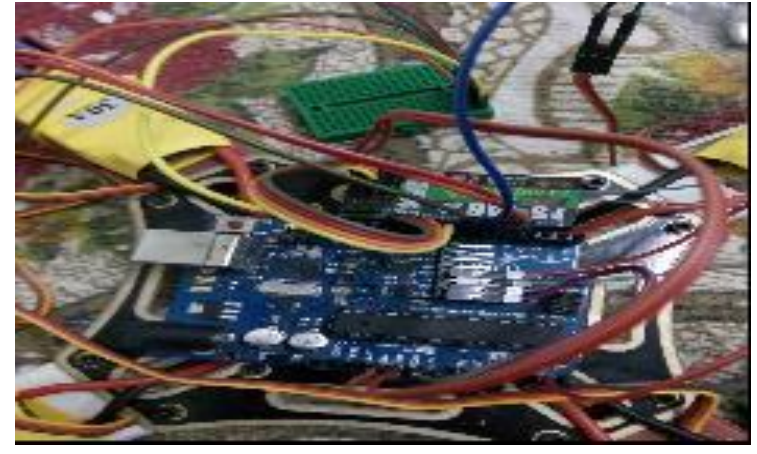

Gambar 2. Mikrokontroler arduino uno

Berikut merupakan pin yang digunakan pada arduino :

Tabel 1. Konfigurasi pin arduino uno

\begin{tabular}{l|ll}
\hline Pin Arduino & Input & Output \\
\hline Pin digital 3 & & ESC 1 \\
Pin digital 4 & & ESC 2 \\
Pin digital 5 & & ESC 3 \\
Pin digital 6 & & ESC 4 \\
Pin digital 8 & Channel 1 & \\
Pin digital 9 & Channel 2 & \\
Pin digital 10 & Channel 3 & \\
Pin digital 11 & Channel 4 & \\
Pin 5v & Vcc receiver & Vcc ESC1, \\
& flysky i6 & ESC2, ESC3, \\
& & ESC4 \\
Vin & Vcc Sensor & \\
Ground & MPU6050 & \\
Gin A4 & Glysky i6 & Ground ESC1, \\
fin A4 & Ground Sensor & ESC4 \\
\hline
\end{tabular}

\section{Sensor MPU6050}

Sensor MPU6050 mempunyai fungsi sebagai accelerometer dan gyro, untuk menentukan posisi yang stabil pada saat robot penjelajah udara melakukan gerakan terbang. Hasil pembacaan sensor MPU6050 terdiri atas besaran arah Pitch, Yaw, dan Roll. Pembacaan sensor MPU6050 dilakukan pada gerakan searah sumbu $\mathrm{X}$ atau searah sumbu $\mathrm{Y}$. Pengujian sensor MPU6050 ditampilkan pada serial monitor arduino dan gerakan sensor diukur dengan penggaris busur secara manual. Gambar 3 dibawah merupakan pengujian MPU6050.

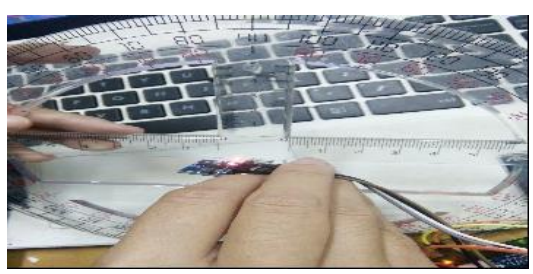

Gambar 3. Pengujian sensor MPU6050 
Hasil pembacaan sensor MPU6050 pada gerakan searah sumbu X, ditunjukkan pada tabel 2.

Table 2. Pengujian dengan gerakan searah sumbu $\mathrm{X}$

\begin{tabular}{c|cccc}
\hline No & $\begin{array}{c}\text { Pengukur } \\
\text { an sudut } \\
\text { gerakan } \\
(\circ)\end{array}$ & $\begin{array}{c}\text { Pembaca } \\
\text { an sudut } \\
\text { Pitch }\end{array}$ & $\begin{array}{c}\text { Pembaca } \\
\text { an sudut } \\
\text { Yaw }\end{array}$ & $\begin{array}{c}\text { Pembaca } \\
\text { an sudut } \\
\text { Roll }\end{array}$ \\
\hline 1. & 0 & 4.61 & 21.32 & 3.97 \\
2. & 30 & 35.50 & 1.30 & 4.35 \\
3. & 60 & 38.86 & 0.02 & 4.27 \\
4. & 90 & 55.25 & 146.47 & 0.41 \\
5. & 120 & 41.65 & 165.12 & 0.02 \\
6. & 150 & 21.10 & 176.40 & 0.25 \\
7. & 180 & 33.65 & 174.32 & 0.03 \\
\hline
\end{tabular}

Dan hasil pembacaan sensor MPU6050 pada gerakan searah sumbu Y, ditunjukkan pada tabel 3.

\begin{tabular}{c|cccc}
\multicolumn{5}{c}{ Tabel 3. Pengujian dengan gerakan searah sumbu Y } \\
\hline No & $\begin{array}{c}\text { Pengukur } \\
\text { an sudut } \\
\text { gerakan } \\
\text { (०) }\end{array}$ & $\begin{array}{c}\text { Pembaca } \\
\text { an sudut } \\
\text { Pitch }\end{array}$ & $\begin{array}{c}\text { Pembaca } \\
\text { an sudut } \\
\text { Yaw }\end{array}$ & $\begin{array}{c}\text { Pembaca } \\
\text { an sudut } \\
\text { Roll }\end{array}$ \\
\hline 1. & 0 & 4.61 & 21.32 & 3.97 \\
2. & 30 & 0.00 & 32.26 & 19.05 \\
3. & 60 & 0.01 & 33.88 & 22.88 \\
4. & 90 & 0.01 & 35.06 & 32.53 \\
5. & 120 & 0.02 & 34.31 & 46.61 \\
6. & 150 & 0.75 & 0.21 & 88.97 \\
7. & 180 & 6.01 & 62.44 & 0.39 \\
\hline
\end{tabular}

\section{Motor Brushless}

Pengujian motor brushless yang digunakan pada robot penjelajah udara dilakukan dengan dua tahap pengujian untuk mengetahui besaran rpm yang dihasilkan motor brushless. Pertama, dengan menggunakan potensiometer untuk setiap motor brushless. Kedua, menggunakan Remote Control fly sky i6 yang telah dikoneksikan dengan motor brushless melalui arduino uno, untuk empat buat motor brushless robot penjelajah udara. Pengujian motor brushless dengan remote control fly sky i6 ditunjukkan pada gambar 4.

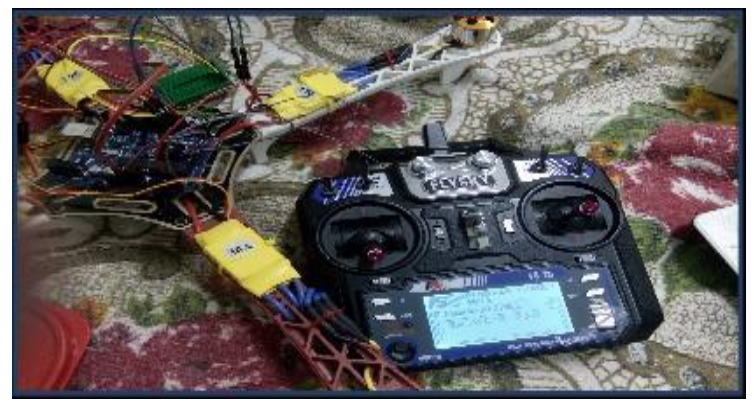

Gambar 4. Pengujian remote control fly sky i6 terhadap perputaran motor
Besar rpm motor yang dihasilkan melalui pengujian dengan menggunakan potensiometer ditunjukkan pada tabel 4 .

\begin{tabular}{l|ll}
\multicolumn{3}{c}{ Tabel 4. Pengujian motor dengan potensiometer } \\
\hline No & Besaran Tahanan dari & RPM Motor \\
& Potensiometer & Brushless \\
\hline 1. & $250 \Omega$ & 337 \\
2. & $500 \Omega$ & 224 \\
3. & $1 \mathrm{~K} \Omega$ & 192 \\
\hline
\end{tabular}

Pengujian rpm motor yang dihasilkan dengan menggunakan remote control fly sky i6 ditunjukkan pada tabel 5 .

Tabel 5. Pengujian dengan Remote Control Fly Sky i6

\begin{tabular}{l|lllll}
\hline No & Thortle & RPM & RPM & RPM & RPM \\
& Remote & BLDC 1 & BLDC 2 & BLDC 3 & BLDC 4 \\
\hline 1. & Rendah & $355-550$ & $353-545$ & $348-543$ & $353-545$ \\
2. & Sedang & $562-1098$ & $568-1089$ & $565-1093$ & $570-1086$ \\
3. & Tinggi & $1145-1459$ & $1139-1455$ & $1143-1458$ & $1146-1461$ \\
\hline
\end{tabular}

\section{Program Kendali}

Program kendali yang digunakan untuk mengatur kestabilan terbang robot adalah PIDfuzzy. Menggunakan aplikasi matlab dengan menginputkan fuzzy toolbox, program fuzzy quadcopter (fuzzydrone2), serta system sllokkuptable pada worksheet. Berikut merupakan gambar worksheet dari matlab. Gambar 5 menunjukkan simulink Using Look Up Table to Implement PID-Fuzzy Contrroller.

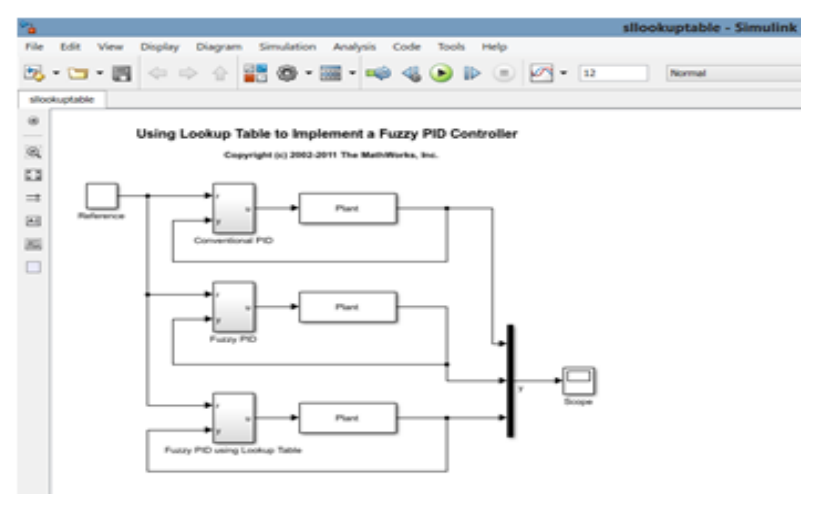

Gambar 5. Simulink implement PID-Fuzzy Controller

\section{Kontroler PID}

Dalam pembuatan robot penjelajah udara, juga dilakukan pengujian dengan menginputkan kontroler PID pada masing masing gain $K p, K i$, dan $K d$. Hasil pengujian diperoleh rise time 6,2 detik. Gambar 6 menunjukkan simulink program untuk kontroler PID sebagai berikut: 


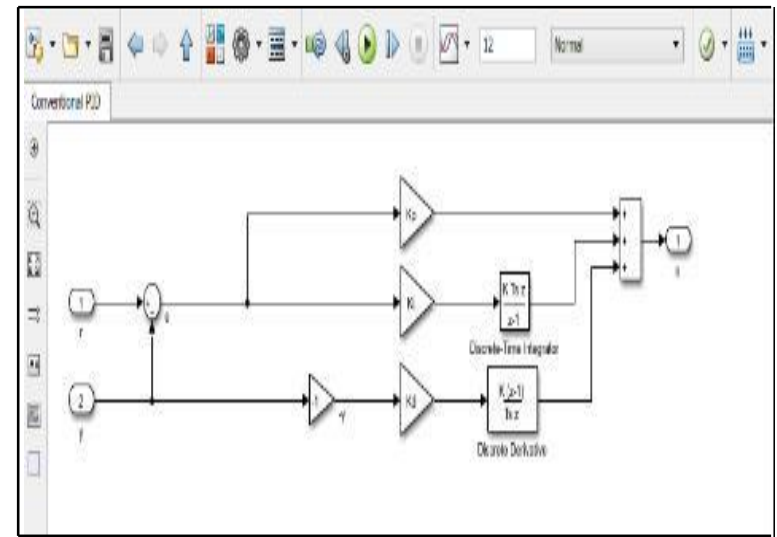

Gambar 6. Simulink PID Controller

\section{Kontroler PID-Fuzzy}

PID-fuzzy controller digunakan simulink yang memiliki fungsi input Fuzzy Inference System (FIS). Pada fungsi tersebut di inputkan toolbox fuzzy serta dilakukan tuning gain PID. Program ini menghasilkan rise time 5,6 detik. Gambar 7 merupakan Simulink program fuzzy-PID serta toolbox fuzzy yang diinputkan pada function FIS.

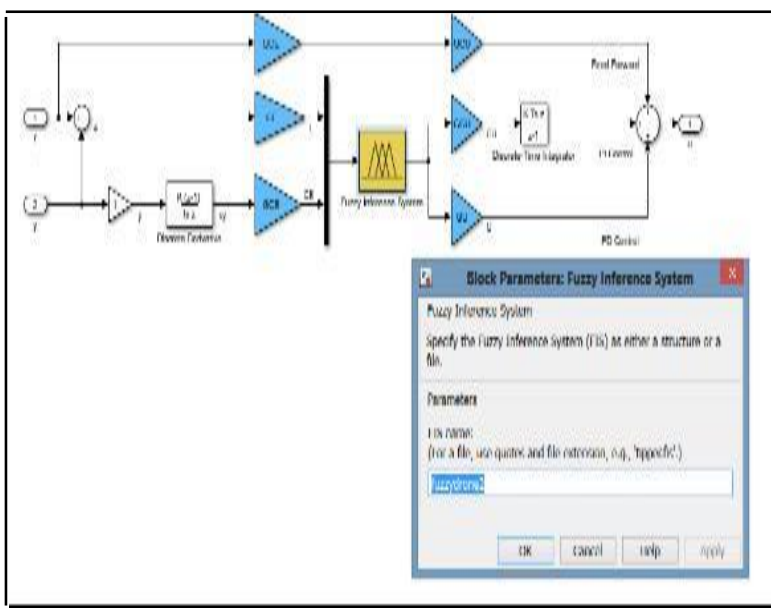

Gambar 7. PID-Fuzzy Controller

Gambar 8, menunjukkan toolbox fuzzy robot penjelajah udara (quadcopter).

\section{Perbandingan Program PID dengan PID-Fuzzy}

Perbandingan antara pengendalian menggunakan kontroler PID dengan PID-fuzzy dapat dilihat pada gambar 9. Pada gambar menunjukkan kontroler PID-Fuzzy (garis merah) menghasilkan keluaran yang lebih baik dibandingkan menggunakan kontroler PID saja. Kontroler PIDfuzzy dapat mencapai nilai rise time lebih cepat serta dapat meredam nilai overshoot dengan baik.

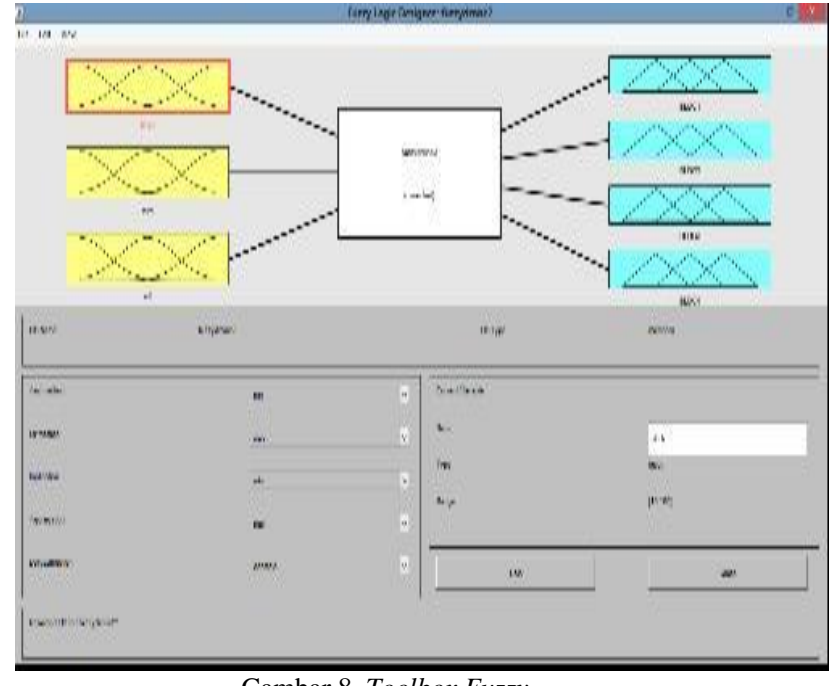

Gambar 8. Toolbox Fuzzy

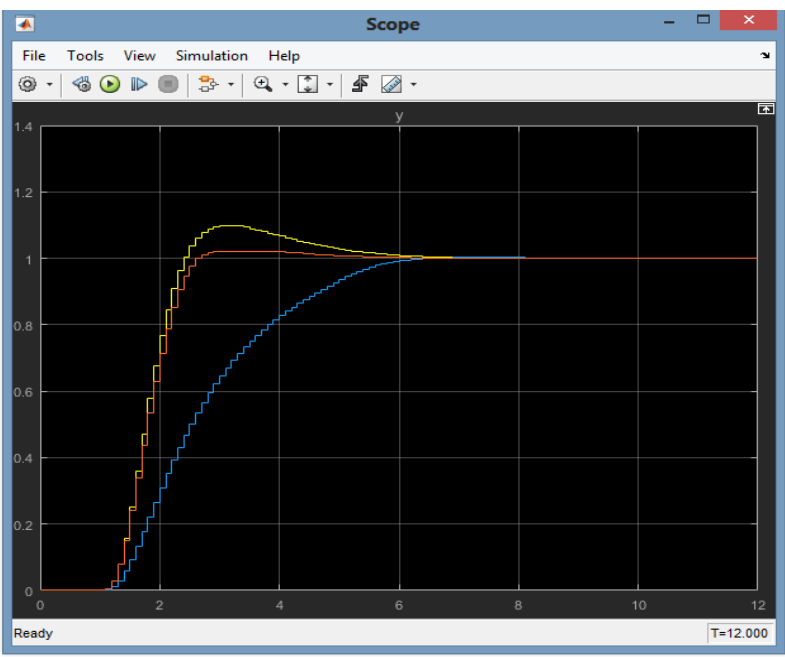

Gambar 9. Grafik scope Simulink look-up table

\section{Perubahan Putaran Motor Sesuai Tuas Sudut Gerak Remote}

Perubahan perputaran motor dilakukan untuk mengetahui bagaimana perbedaan keempat motor brushless $D C$ sesuai gerakan tuas sudut gerak di remote control fly sky i6. Pengujian ini dilakukan dengan input program flight controller yang telah ditanamkan control PID-fuzzy. Hasil pengujian didapatkan hasil perputaran motor DC yang tampil di serial monitor ditunjukkan pada tabel 6 .

Tabel 6. Perputaran Motor BLDC dengan PID-fuzzy controller

\begin{tabular}{l|cccc}
\hline Gerakan & $B L D C$ & $B L D C$ & $B L D C$ & $B L D C$ \\
$\quad$ Tuas & 1 & 2 & 3 & 4 \\
\hline Kanan & 1.550 & 1.490 & 1020 & 1123 \\
Kiri & 1120 & 1034 & 1580 & 1485 \\
Atas & 1487 & 1090 & 1558 & 1043 \\
Bawah & 1087 & 1580 & 1488 & 1032 \\
\hline
\end{tabular}

\section{KESIMPULAN}

Arah terbang robot penjelajah udara dapat berjalan dengan baik karena adanya input dari sensor MPU6050 yang mempunyai pembacaan gyroscope dan accelerometer yang dikontrol dengan 
mikrokontroler Arduino Uno. Kendali jarak jauh remote control fly sky i6 dapat digunakan dengan baik, setiap perubahan throttle dapat mempengaruhi perubahan kecepatan motor brushles DC. Kendali PID-fuzzy pada robot dapat memberikan kestabilan terbang pada robot penjelajah udara (quadcopter), dengan kendali fuzzy diinputkan kedalam FIS simulink untuk mendapatkan nilai tuning PID yang baik. Nilai gain PID yang didapatkan akan mempercepat rise time dan meredam nilai overshoot. Agar kestabilan terbang dari robot penjelajah udara ini lebih baik perlu ditambahan sensor jarak untuk membaca ketinggian sehingga robot dapat mempertahankan posisi pada ketinggian tertentu.

\section{DAFTAR PUSTAKA}

HARYANTO, L., YUSUF, Y.G., WICAKSONO, H (2014). Sistem Fuzzy-PID Controller Untuk Menjaga Ketinggian Terbang Quadcopter. Prosiding Seminar Nasional Teknologi Terapan SV UGM, 1-5.

KUMAR, K.S., RASHEED. M., KUMAR, R.M. M (2014). Design and Implementation of Fuzzy Logic Controller for Quad Rotor UAV. Proceedings from ICRSET 2014 : 2nd International Conference on Research in Science, Engineering and Technology (ICRSET'2014). $114-120 . \quad$ DOI: http://dx.doi.org/10.15242/IIE.E031459

SETYAWAN, G.E., SETIAWAN, E., KURNIAWAN, W (2015). Sistem Kendali Ketinggian Quadcopter Menggunakan PID. Jurnal Teknologi Informasi dan Ilmu Komputer, 2(2), 125-131. DOI: http://dx.doi.org/10.25126/jtiik.201522144

YUSIVAR, F., JEPRY. J (2010). Perancangan Pengendali PID Pada Proportional Valve. Real Time Measurement and Control Research Group. Departemen Teknik Elektro, Fakultas Teknik Universitas Indonesia.

RICARDO, I. N., ASTOWULAN, K., Iskanda, E (2010). Perbandingan Kontrol Manuver dan Pendaratan Quadrotor dengan PID, Gain Scheduling, dan PID Sinyal Kontrol Termodifikasi. Jural Jurusan Teknik Elektro ITS, 1-6.

KUSUMADEWI, S (2002). Analisis dan Desain Sistem Fuzzy Menggunakan Toolbox Matlab. Graha Ilmu, Yogyakarta.

BINUS (2012, Mei 2). Pemodelan Dasar Sistem Fuzzy. Dipetik Mei 5, 2018, dari http://socs.binus.ac.id/2012/03/02/pemodel an-dasar-sistem-fuzzy/

PUTRA, E.P (2013, Nov 21). PID (ProportionalIntegral-Derivative) Controller. Dipetik Juni 10, dari https://putraekapermana.wordpress.com/20 13/11/21/pid/ 